\title{
Manuel Gálvez y Eduardo Mallea
}

L hecho de unir a Gálvez y Mallea en un mismo título es sin
duda fácil de justificar, siempre que nos atengamos a razones inmediatas; pero quizá las haya más encubiertas y que requieran mayor detención.

Los vínculos más cercanos entre estos dos escritores son, por supuesto, los de patria y de profesión, siendo ambos novelistas ante todo argentinos; pero han sido además, y cada uno en su época, pilotos de derroteros literarios, y por lo tanto son merecedores de un estudio más amplio que si hubiesen sido simples pasajeros. Precisamente por este hecho -el de compendiar determinadas etapas del arte de novelar- es lícito pretender llegar a conclusiones generales. Es de esperar que en la unisonancia, contrapunto o disonancia de estas voces ejemplares se pueda percibir un ritmo del pensamiento argentino en el pasado medio siglo.

Nos podríamos fijar desde luego en el trecho que va de Gálvez a Mallea : i tantas y tan accidentadas leguas que por poco se desanima todo intento de comparación! Una distancia de treinta y un años, pues nació Gálvez en 1882 y Mallea en 1903, es en cualquier época imponente; pero es claro que con la actual aceleración de los cambios culturales se vuelve casi definitivo. Hoy las generaciones pronto se miran como extranjeras. Gálvez imperó desde el 10 hasta mediados del 20 del presente siglo, tiempos de enorme prosperidad para la economía argentina, ya entrada en adolescencia Buenos Aires con sus dominios; tiempos en que el agregarse de gente y cosas a la nación hizo del realismo literario un concepto no solamente aceptable sino en efecto inevitable. Mallea, en cambio, extiende su hegemonía sobre los años 30 a 40, tiempos de crisis y aflicción, a partir de la tremenda depresión mundial y finalizando con la última guerra y 
su secuela de horrores; tiempos en que, sobra decirlo, un profundo sentimiento de desmayo espiritual impele al pensamiento humano desde el mundo interior hasta su universo interior.

Algunos de los temas tratados por estos autores son también bastante disímiles. Gálvez busca materias sociológicas en que sobresalga la necesidad de reformas directas y prácticas, como por ejemplo en Nacha Régules, Historia de arrabal y La pampa y su pasión. $\mathrm{Ni}$ temas ni actitud son compartidos por Mallea, pues él no es un reformador de esta especie. Tampoco le atraen los encantos del asunto histórico, que cada vez más reclama la atención a Gálvez. De ahí que la escena pintada por Mallea sea de extensión más limitada, aunque de perspectiva más profunda. A Gálvez le falta capacidad para entrar en terrenos donde Mallea se siente más a sus anchas, es decir: en la revelación larga y pausada del espíritu humano, donde el cuerpo se circunscribe a una zona de acción bastante chica. Nótese, sin embargo, una excepción en el repertorio de Gálvez: Miércoles Santo, novela descollante entre las suyas por su notable intensidad psicológica. Frente a la postura sumamente razonable que caracteriza a Gálvez, la sensibilidad de Mallea para lo misterioso le conduce hasta situaciones donde la responsabilidad de los actos recae sobre el individuo y no sobre la sociedad que aparentemente le sostiene.

Ya sea la causa interna o externa, las configuraciones de la conducta humana pueden someterse por igual a la observación; y la honradez de estos dos autores los guía hasta la misma fuente: la vida en Argentina. Como son, además, habitantes de Buenos Aires desde hace muchos años, la ciudad porteña es su mirador y su escala de valores. Dan fe y testimonio de las costumbres en todo el ámbito burgués, corazón del país; y mientras con la mirada absorben este panorama se preocupan, con dolor, por la salud espiritual de su patria. En este sentido son admirablemente patrióticos, tienen valor para echar su suerte con la Argentina, de buena gana, y lo que es más, sin incurrir en xenofobia sino de cuando en cuando.

Para poner de manifiesto los rasgos de su parentesco literario, nada mejor que fijarnos en cuántas veces han utilizado el mismo diseño básico para elaborar su composición. Estas figuras, paralelas o entretejidas, me parece que no son fortuitás sino facetas de una tradición nacional a través de su literatura. 
Una de estas figuras es el journal intime. En 1910 Gálvez publicó El diario de Gabriel Quiroga. Bajo la influencia parcial de Amiel, con muchos recuerdos de Stendahl, Gálvez presenta la supuesta autobiografía episódica de un joven argentino, quien desde diversos sitios del país escribe sus crónicas al azar sobre esto y lo otro. Es una perceptividad que cavila en Dios, el hombre y cuanto existe de intermediario. He aquí el peregrino que toma a la Argentina entre manos, la inspecciona a la vez con complacencia y pena; que aprende así la geografía de su propio espíritu. Pasemos ahora a la Historia de una pasión argentina, ese libro extraordinario de Mallea: mucho más extenso, enormemente más complejo, pero asentado sobre los mismos cimientos. Aquí de nuevo se ve el narrador que habla en primera persona; de nuevo andante, de nuevo analizando, al escudriñar a su patria con pupila ansiosa, midiéndola con su propia alma. Ni uno ni otro de estos libros pueden considerarse pura ficción ni pura autobiografía sino un género híbrido, pues son obras de juventud en plena rebelión contra cohibiciones formales, que precisan dilatarse antes que puedan ređucirse esquemáticamente después. Por éso no extraña que de la madeja enmarañada cada autor entresaque el hilo de obras posteriores: Gálvez, cuando menos, La maestra normal y El mal metafísico, y Mallea, La había de silencio.

En esto aparece la segunda repetición de figuras: El mal metafísico (1916) y La bahía de silencio, posterior en veinticinco años; dos composiciones mayores en las cuales vierte el autor sus sentimientos más vivos, están planeadas de conformidad con un concepto que, parafraseando a Joyce, podríase llamar "la derrota del joven artista". Carlos Riga, el poeta de alma tierna a quien aplasta la sociedad al procurar crear la belleza desinteresada, es un precursor de Martín Tregua, el novelista cuyo mensaje de fortaleza anímica se rechaza igualmente. Ciertos pasajes de la novela anterior vuelven a aparecer substancialmente en la posterior: la casa de huéspedes con sus moradores abigarrados, las clases universitarias, los cenáculos donde se discute arte y vida, la fundación de la revista literaria, su derrumbe, la obra personal de inspiración febril, su publicación, la vuelta apenada a las librerías donde está de venta, y la postrera. comprensión de la derrota. Y en cada libro suena sostenida, como nota de órgano, un amor imposible e idealizado que vibra por de- 
bajo de todo cambio en la condición del protagonista: Riga que sueña con su Lita; Tregua cuya fantasía vuela tras de su misteriosa "usted".

El tercer entrelazamiento de figuras pone al revés el orden de prioridad. Hasta aquí Gálvez ocupa la escena primero; mas cuando se trata del tema de soledad, se truecan los papeles. La colección de cuentos que Mallea publicó en 1936 bajo el título de La ciudad junto al río inmóvil -comprende narraciones aparecidas en periódicos desde 1931--, significó no sólo una nueva técnica para su autor sino además un nuevo tema para la ficción argentina. A través de su introspección y sus lecturas casi ilimitadas, Mallea había alcanzado a comprender la acongojada soledad del hombre en un universo frío e indiferente; y los cuentos ilustran esta creencia, bastante próxima a la filosofía existencialista. Hombres y mujeres, solteros o casados, sienten la garra impía de la soledad y con sus heridas van a perderse en la lejanía. Entonces Gálvez, en forma que sugiere la posibilidad de que se apresuraba a aprovechar un nuevo hallazgo -aunque es cierto que lo había rozado ya en El mal metafísico-, saca a luz Hombres en soledad (1938) donde alrededor del título agrupa varios casos vitales con el propósito evidente de recorrer la gama. Aislados uno de otro, esta gente vaga por delante del lector, cruza y desaparece. Es notable que aquí, entre otras fallas de Gálvez, se halle la de no fundir las partes en una totalidad coherente, de modo que el efecto es el de varias biografías mal articuladas, por lo que la estructura se asemeja a la del libro malleano.

Así en tres de los ejemplos más destacados los procedimientos de Gálvez y de Mallea parecen converger; pero quedan por valorizarse sus ideologías, de suma importancia en autores tan intelectuales. Siempre limitándonos a muestras lo más selectas, podríamos tomar en cuenta la ciudad como fuerza generatriz. Resalta desde luego una similitud: los dos escritores compenetrados de Buenos Aires, 10 usan como premisa mayor. Entre los límites de sus mejores novelas, Gálvez llega a La Rioja y Córdoba, y Mallea no deja de visitar Bahía Blanca, pero los novelistas se comparan mejor en stus relaciones con la gran urbe porteña. Reaccionan con admiración recelosa y atracción inquieta. Con familiaridad casi cariñosa van marcando los nombres de calles, edificios, parques y vías de agua; prospera su imaginación contemplando la fisonomía colosal. Mas 
en cambio no quieren admitir que Buenos Aires les inspire verdadero amor. "iAh, Buenos Aires!”- - piensa un protagonista de Gálvez-, " Era la sirena espléndida y terrible! Ella sacaba de sus hogares provincianos a innumerables buenos muchachos, los atraía con su canción fascinadora, les poblaba la cabeza de ilusiones, los dejaba luego, enterrados en una triste oficina para siempre, sin más esperanza que la jubilación, sin otra gloria que un irrisorio sueldo". ${ }^{1}$ Y exclama Mallea: " $\mathrm{A}$ h, ciudad, ciudad, enorme ciudad opulenta, ciudad sin belleza, páramo, valle de piedra gris: tus tres millones de almas padecen tantas hambres profundas " $2 \mathrm{Y}$ compara a Buenos Aires con una mujer que se entrega a cuantos halagan su capricho, pero que hacia los demás guarda una soberbia helada. Gálvez recibe prestado de Verhaeren el epiteto "ciudad tentacular".

Buenos Aires se muestra hosca a todos en cierto grado; mas para tres clases de personas se vuelve feroz: el inmigrante, el provinciano y el intelectual, siendo éstos quienes osan ponerla a prueba. Con agudeza Mallea entiende la desdicha del primer grupo, por casos como el de Jacobo Uber y el del viejo Ricarte, y revela admirable simpatía por sus problemas de adaptación, aun cuando pudo ceder al chauvinismo, por ser de una familia argentinísima, entroncada con la de Sarmiento. Gálvez, en cambio, se ha permitido un acento petulante al calificar a los inmigrantes de intrusos y propagadores de un cosmopolitismo perjudicial, y su recelo se extiende, por desgracia, a lo racial. En cuanto a los demás grupos rechazados por Buenos Aires, él y Mallea concuerdan más o menos: y tanto más cuando se trata de personas que son al mismo tiempo intelectuales y provincianos, pues los dos novelistas combinan estas cualidades y por lo visto han sufrido en su carne el desprecio metropolitano. No nacieron en Buenos Aires ni se formaron allí. Gálvez salió de Paraná a Santa Fe y por fin a la gran ciudad, antes de cumplir veinte años de edad, y Mallea se marchó de Bahía Blanca a los doce. A pesar de establecerse en la metrópoli, realizar su carrera en ella y tener su espíritu imbuído de su atmósfera, no quieren olvidar lo que significa ser forastero en una zona cultural tan densa.

El tema de aislamiento espiritual entonces llega a ser un componente en ambas ideologías. La interpretación del tema, sin embargo, revela divergencias. Para Mallea se trata nada menos que de una participación total, porque cree que la soledad no es accidente 
sino esencia. El hombre es el no deseado. Para él la existencia es una sorpresa constante y triste; sus relaciones con los demás dejan de apaciguar sus intimas necesidades, pues aunque anhela fundirse con otros seres por medio del amor, no es capaz de amar, y para colmo se cree culpable de algo que es el fuego fatuo de su intelección. Acaba por convencerse de que su culpa consiste simplemente en vivir. No es así Gálvez. Donde se ocupa plenamente del asunto es en Hombres en soledad, y aquí lo analiza sensata y serenamente, reduciéndolo todo a un "mal", es decir, un desarreglo de lo normal y siempre por causas accidentales. En esta novela un intelectual se ve desterrado por soberbio e incomprendido; una esposa, por ser culta con un marido lerdo; otra, por ser espiritual pero obligada a tratar a hedonistas. Todos aprietan su tristeza al corazón desbordante; son más solitarios por las tardes del domingo; y así por el eśtilo. La soledad, en fin, es sinónimo de fastidio, melancolía, humillación y puritanismo. En El mal metafísico el poeta está sencillamente enfermo, incurablemente, por supuesto, acaso psicosomáticamente, pero de todos modos abierto a la diagnosis.

En cuanto a una causa contribuyente al dolor general - como el materialismo- el acuerdo de nuestros autores es un dúo apasionado. Página tras página, suceso tras suceso, tocan a rebato. Los argentinos se destruyen por su apego a los valores materiales, ya sean dinero, ropa, casas, poder político o sexualidad. Para Mallea el peor enemigo del alma es la carne, y los hombres nobles y castos de Gálvez sacuden el cautiverio de la voluptuosidad para escuchar. el cántico espiritual. Y los dos evocan a Celui-qui-ne-comprend-pas: en Gálvez, con el disfraz de "unitario"; en Mallea, con el anatema de "visible". El estrago del país es fatal mientras los ciudadanos sigan atesorando locamente las vanidades de este mundo.

De tal modo acosado por sus aflicciones, los personajes de Gálvez y Mallea se encaminan a tientas hacia una solución. Las respuestas que se formulan son claves lúcidas a la $W$ eltanschaunng de cada autor. Juntos rehusan la solución de Europa, a despecho de ser atrayente. La emigración, dice Gálvez, sirve tal vez en casos individuales; pero es difícil que convenga a toda una nación. Tanto él como Mallea aceptan la idea de que lo valedero para Europa puede no valer para la Argentina; y por dar relieve a esta posibilidad, crean personajes que después de hacer la travesía atlántica vuelven com- 
pungidos, con el mensaje de que la Argentina tiene que llevar a cuestas el peso de sus propios cuidados.

Luego se distancian Mallea y Gálvez. Este, con sus convicciones pragmáticas, aboga por medios concretos: mejorías sociales, prestigio para la intelectualidad, ortodoxia religiosa y disciplina. $Y$ lástima que a veces su apoyo de estos valores le haya conducido al borde del fascismo. Mallea, por'su parte, no logra hallar una solución tan a flor de piel. Compasión, eso sí; pero sabe que "nadie influye en nadie". ¿Humildad, sinceridad, autenticidad? Sabe distinguir que tales abstracciones no aplacarán jamás el tormento personal. En un intervalo de su desarrollo mantenía que el "silencio", o paciente aceptación de la derrota secular, era la única solución fuera de la locura o el suicidio. Mas recientemente se inclina a pensar que el individuo puede retirarse a una "torre", donde ajeno voluntariamente del mundanal ruido puede mantenerse alerta y en contacto con lo de afuera.

Todo esto nos lleva al punto donde Gálvez y Mallea están más desavenidos, y es la conexión del novelista con sus novelas. Ha mantenido Gálvez desde un principio que autor y ficción deben guardarse bien separados. Observó una vez: "E1 novelista ha de ver las cosas desde arriba, en su conjunto y en sus detalles. Ha de percibir los acontecimientos desarrollándose, el hilo que los une, la manera cómo unos y otros se encadenan y se mezclan... Ha de ser un poco filósofo y, puesto que está por encima de todas las cosas, estudiarlas con amor pero sin tomar partido por ninguna de ellas". ${ }^{3}$ Esta es la razón de por qué Gálvez parece tan deleznable al estudioso que prefiera que un autor se declare rotundamente en pro o en contra. El temple de Mallea es otro. Se da el nombre de agonista, el que entra a bregar, que sufre a medida que sus personajes, que está totalmente engagé, que es su novela. Mientras que Gálvez, por una parte, guarda sus opiniones directas casi siempre para ensayos, Mallea con frecuencia mezcla el ensayo, la autobiografía y la ficción, de modo que muchos de sus escritos, como Nocturno europeo y Meditación en la costa, son imposibles de encasillar; ni querría Mallea que se encasillen. En un escritor se halla un realismo objetivo a base del determinismo; en el otro, un fenómeno más nuevo, el lirismo de lo inconsciente, surgiendo de la búsqueda a veces irracional de la existencia legítima. 
A pesar de que están tan alejados estos autores en ciertos sentidos, hablan con acentos de curiosa semejanza, pues son los acentos de la Argentina. Su esfera es bastante restringida, y dentro de ella como moralistas se dedican al escrutinio del alma argentina. Puede que el mundo se canse del moralista; máxime si como estos dos su vis cómica da poco de sí. En todo caso, no sería aventurado decir que Gálvez ya no se comunica efectivamente con la Argentina joven $y$ artista, $y$ en años recientes Mallea ha encontrado alguna resistencia aun en su propio círculo literario. Es posible que la palabra pase a escritores más donairosos e imaginativos; mas sería de lamentar que se tuvieran en menos las innegables aportaciones. de estas dos mentes serias.

$$
\begin{gathered}
\text { ARnold Chapman, } \\
\text { University of California, Berkeley. }
\end{gathered}
$$

\section{$\mathrm{NOTAS}$}

1 El mal metafísico. Buenos Aires, 1922, p. 13.

2 Historia de una pasión argentina. Buenos Aires, 1944, p. 50.

3 Prólogo a Un perdido de Eduardo Barrios. Buenos Aires, 1921, pp. 3-4. 